\title{
MEINONG'S VERSION OF THE DESCRIPTION THEORY
}

\author{
Arkadiusz Chrudzimski \\ Philosophy / U. of Szczecin, U. of Salzburg \\ A-5020 Salzburg, Austria \\ ARKADIUSZ.CHRUDZIMSKI@SBG.AC.AT
}

\begin{abstract}
About 1904 Meinong formulated his most famous idea: there are no empty (non-referential) terms. Russell also did not accept non-referential singular terms, but in "On Denoting" he claimed that all singular terms that are apparently empty could be explained away as apparent singular terms. However, if we take a more careful look at both theories, the picture becomes more complex. It is well known that Russell's concept of a genuine proper name is very technical; but this is also true of Meinong. Also, according to Meinong we can refer "directly" only to a very special category of ontologically simple objects. However, a very important difference is that, in the domain of Meinongian objects, a plurality of objects always corresponds to each description. Thus, if Meinong were right, there could be no definite descriptions. If we narrow the domain of reference to existent objects, we can secure the uniqueness of the reference object by specifying a collection of predicates that is contingently satisfied by only one (existing) object. But if we operate in the domain of all possible objects, we have to specify all properties that are had by the object in question. It turns out that such a "Leibnizian" specification amounts to the complete description of a possible world.
\end{abstract}

\section{AT FIRST SIGHT}

A $s$ is well known, according to Meinong there are no nonreferential nominal phrases. No matter how the putative reference is specified, it could always be found in the Meinongian domain of Außersein. To be sure, some of these objects, like centaurs and golden mountains, do not exist, but all of them enjoy the status of Außersein ( $c f$. Meinong 1904). In The Principles of Mathematics (1903) Russell held a similar position, but just two years later, in "On Denoting", he criticized the Meinongian approach and formulated the 
theory of definite descriptions to the effect that all singular terms that are apparently empty could be reinterpreted as apparent singular terms. In this way he hoped to get rid of Meinongian objects "beyond being and non-being".

Russell's famous technique consists in replacing singular terms by predicates. The sentence:

The golden mountain is high

turns in Russell's hands into:

There is an $x$ such that ( $x$ is of gold, $x$ is a mountain, $x$ is high, and whatever is both of gold and a mountain is $x$ ).

Symbolically:

$$
\exists x[G x \& M x \& H x \& \forall y(G y \& M y \supset y=x)] .
$$

The exclusivity condition involved in Russell's translation: " $\forall y(G y \& M y$ $\supset y=x$ )" says that if there were more than one golden mountain, then the whole sentence "the golden mountain is high" would be false.

At first sight the similarities and differences between Meinong and Russell can be summarized as follows:

(I) Both claim that there are no empty singular terms.

(2) Meinong introduces for each apparently non-referential singular term an object "beyond being and non-being".

(3) Russell explains such terms away as merely apparent singular terms.

In short, Meinong expands his universe, while Russell narrows the category "singular term". This can be illustrated by the following two pictures of the semantic relations involved in the use of the sentence under consideration: 


\section{Meinong's Semantics I:}

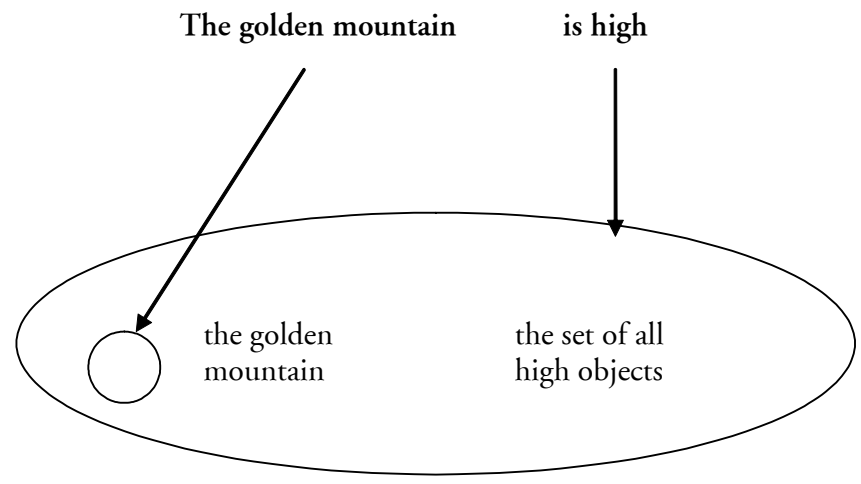

\section{Russell's Semantics:}

\section{The golden mountain is high}

is analyzed as

$\exists x[G x \& M x \& H x \& \forall y(G y \& M y \supset y=x)]$

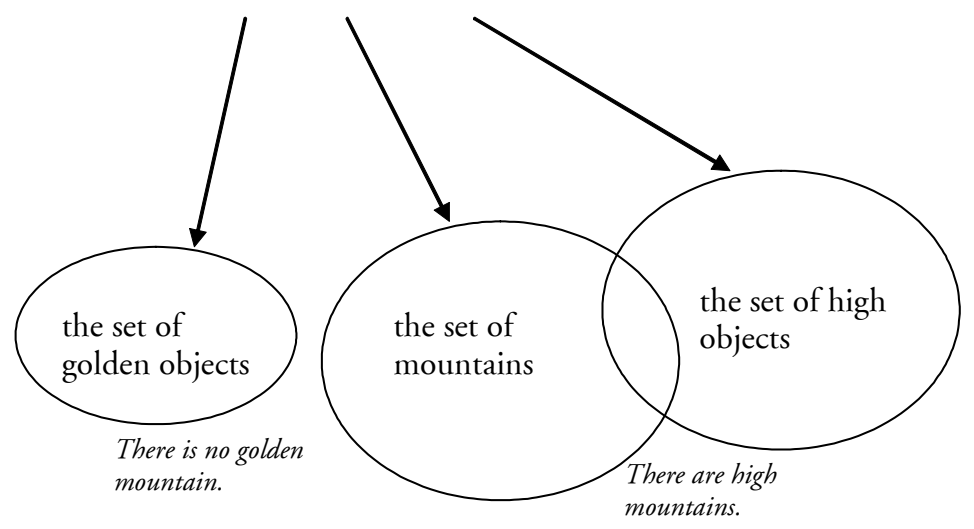




\section{MEINONG'S VERSION OF THE DESCRIPTION THEORY}

It seems thus that there is a fundamental discrepancy between the semantics proposed by Russell and Meinong. However, the picture sketched above is too simple. If we take a more careful look at both theories, we find many unexpected similarities. It is well known that Russell's concept of a genuine proper name is very technical; but exactly the same holds for Meinong's. Also, according to Meinong we can refer "directly" only to a very special category of ontologically simple objects. All reference to the composed individuals we ordinarily take ourselves to refer to has to be mediated by constructions that behave very similarly to Russellian descriptions.

Beginning with the first edition of Über Annahmen (1902), Meinong developed an ontology according to which each common-sense individual is in point of fact a state of affairs (Meinong's term for a state of affairs is "Objektiv") "composed" out of simple elements which correspond roughly to the (ontologically simple) properties and relations. Meinongian states of affairs could be thought of as "bundles" of simple objects bundled by a peculiar relation that nowadays is commonly called "concurrence" or "compresence". This bundling relation is external in Russell's sense. It is not implied by the natures of the bundled constituents. ${ }^{\mathrm{I}}$

Complementing this ontology, Meinong has a peculiar theory of intentionality. He claims that only such simple elements could be given to the human mind by a nominal intentional state (presentation or idea, which Meinong calls Vorstellung). A composed entity could be given only by a propositional attitude (judgment or assumption-Meinong's Urteil or Annahme). Meinong's mature ontology and theory of intentionality thus resemble very closely those found in Wittgenstein's Tractatus.

The most striking feature of this theory of intentionality, developed in detail in the second edition of Über Annahmen (I9IO), is that the general form of a propositional attitude corresponds almost exactly to the Russellian form (cf. Chrudzimski 200I). Also in Meinong's eyes the sentence:

The golden mountain is high

${ }^{\text {I }}$ Cf. Russell, "Some Explanations in Reply to Mr. Bradley" (Papers 6). Meinong's term for external relation is "real relation"; $c f$. Chrudzimski 2005 b. 
has as its deep logical form something like:

There is an $x$ such that ( $x$ is of gold, $x$ is a mountain, $x$ is high).

Symbolically:

$$
\exists x[G x \& M x \& H x] .
$$

Two differences between Meinong and Russell have to be stressed here. The first (less important) difference is that in Meinong's notation each predicate should be split into a nominal part and a copula. This has to do with the fact that Meinong distinguishes two forms of a property (or relation), but in the following I will neglect these subtleties. The second (more important) difference is that Meinongian quantifiers couldn't in general be interpreted in the standard Quinean way. How exactly should they be interpreted is a difficult matter, but in any event they do not imply anything about the existence of the quantified entities (cf. Chrudzimski 2003, 2005a).

Consequently, we are offered the following picture of intentionality (we pretend that the properties involved are simple):

\section{Meinong's Semantics IIa:}

The golden mountain is high

$$
\downarrow \text { is analyzed as }
$$

$\exists x[G x \& M x \& H x]$

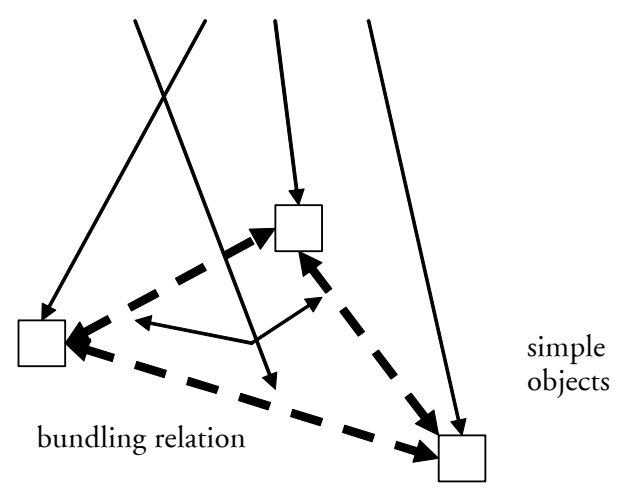


The scheme is to be interpreted as follows. Predicates (" $G$ ”, “ $M$ ”, " $H$ ”) refer to the corresponding simple objects (properties), and the quantifying structure "says" that these simple objects are united by a peculiar relation (let's call it "concurrence") which makes them into constituents of one composed object (which, according to Meinong, is in its core a state of affairs). Therefore we can imagine that the quantifying structure "refers" to this unifying relation. It goes without saying that in Meinong's universe there is a corresponding composed object - a high golden mountain.

\section{NO DEFINITE DESCRIPTIONS}

However, there is also a third (maybe the most important) difference between Meinongian and Russellian descriptions. In Meinong's version of the description theory there is no exclusivity clause: $\forall y(G y$ \& $M y \supset$ $y=x$ ), and indeed in his system there is no place for such a condition. The reason is Meinong's (in)famous principle of the freedom of assumption. The principle states that everything without exception could be assumed, or correlatively that for each assumption there is an object "beyond being and non-being" which fulfils the assumed conditions.

Now imagine that we had at our disposal a Russellian exclusivity clause. In this case we could make the following assumption:

The lake at the border between Canada and the UsA is beautiful.

We can see immediately that the principle of the freedom of assumption would be violated, for even in our world of existing objects there is more than one such lake. That means that there is no unique object which could be designated as the target entity of the assumption in question, which contradicts the principle of the freedom of assumption.

It is therefore obvious that we are by no means fully free to use the definite article, and it is important to observe that in Meinong's universe any use of this article will always be idle. The sad truth is that, in the domain of objects "beyond being and non-being", a plurality of objects always corresponds to each Russellian description.

Just take an arbitrary description $D$ specifying some properties of an object. No matter which properties you choose, you can always imagine an object that has all properties specified by $D$ and, in addition to them, a certain supplementary property $F$. This object will, of course, satisfy $D$. 
But now imagine an exactly similar object lacking $F$. This object will also satisfy $D$. Thus we already have two objects satisfying description $D$, and the same reasoning could be repeated for each further property not already included in $D$. It goes without saying that each of these objects will be a legitimate citizen of the Meinongian realm of Aussersein.

So if Meinong were right, there could be indeed no definite descriptions. The consequence is that Meinongian objects can be "sorted out" or "distinguished" only by means of an indefinite description. We can think only of " $a$ golden mountain" or of " $a$ us president". Within the framework of a Meinongian theory of intentionality there is simply no conceptual structure corresponding to the definite article "the". It means that all sentences with definite articles, like "the golden mountain is high", which have been used in the preceding sections of this paper have a very misleading surface structure. If we were to make their deep logical grammar conspicuous, then the definite article should in each case be replaced by an indefinite article. Once more: in Meinong's universe there is simply no place for the golden mountain.

\section{THE EXISTENCE PREDICATE}

Nonetheless, there are certain ways in which even a Meinongian could specify a singular object. To do this he has to narrow the domain of reference by placing certain unusual, "extra-nuclear" (außerkonstitutorische) predicates (like "exists", "complete" and "possible") in the scope of the description.

In the first case (when we place the predicate "exists" in the scope of the description) we shift from Soseinsmeinen to Seinsmeinen (i.e. from intending of so-being to intending of being). In so doing we are claiming not only that an object is so-and-so but also that such an object exists. Consequently we not only pick out a state of affairs in the realm of Außersein, we also claim that this state of affairs obtains. As Meinongian quantifiers have, in general, no existential import, we must do this with help of the existence predicate ("E!") in the following form:

$$
\exists x[G x \& M x \& H x \& \mathrm{E} ! x]
$$

The picture of Meinong's semantics for a Seinsmeinen looks like this: 


\section{Meinong's Semantics IIb:}

A golden mountain $I S$ high

$$
\downarrow \text { is analyzed as }
$$

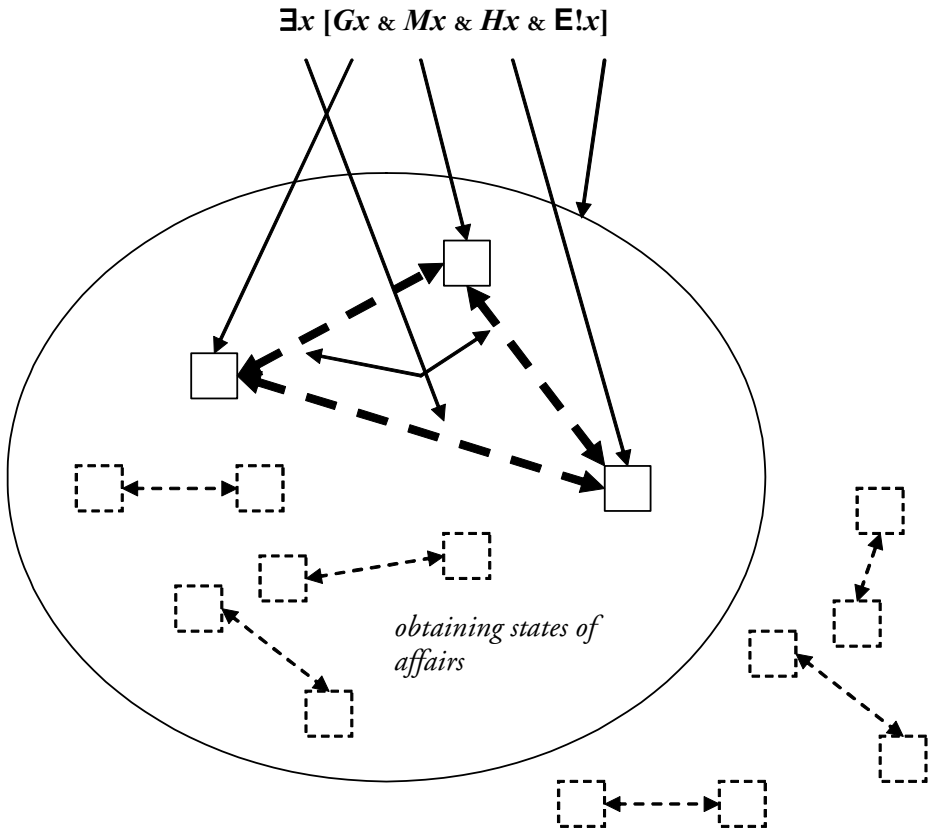

The existentially loaded big "IS" has been analyzed as inserting the existence predicate "E!" in the scope of description. Its "semantic work" consists in introducing the set of obtaining states of affairs as a semantic value which is crucial to determining the truth value of the whole sentence. The sentence is true if and only if its state of affairs is to be found within the restricted realm of the obtaining states of affairs.

There are, of course, many states of affairs of the specified structure "beyond being and non-being". But it is possible that among them there is only one obtaining state of affairs. In this case we can say that we succeed in picking up a singular existing object.

In the case of a pure Soseinsmeinen it is of no importance whether the intended state of affairs obtains or not, and, as Meinong's universe is allinclusive, for each pure Soseinsmeinen, there is a corresponding state of 
affairs beyond being and non-being. This is the background of Meinong's (at first sight rather puzzling) claim, that any old Soseinsmeinen is condemned to be a priori true.

\section{COMPLETENESS}

Now we are moving forward to the second way of singling out a singular object which has to do with the next extra-nuclear predicates "possible" and "complete". But first a few words about Meinongian completeness, which has nothing to do with completeness of logical calculi.

After Über Annahmen Meinong's semantics became increasingly more complex. Around 1907 he explicitly distinguished between complete and incomplete objects and, as a result, complicated enormously his account of intentionality. According to this view, developed in detail in his book Über Möglichkeit und Wahrscheinlichkeit (I9I5), a state of affairs intended in a typical intentional state as "its nearest object" is incomplete. No finite mind is able to describe its object completely. But every such intentional state includes implicitly an assumption that the "true" object which is referred to in this state is to be complete. The underlying intuition is that we never think of incomplete cats or dogs, and this sounds very plausible indeed.

According to this new picture, intentionality does not stop at the incomplete state of affairs (Meinong's objective) but aims "through it" at a complete one. If we symbolize "the completeness property" as "CPL", we obtain the following forms:

Soseinsmeinen: $\quad \exists x[G x \& M x \& H x \&$ CPL $x]$

Seinsmeinen: $\quad \exists x[G x \& M x \& H x \& \mathrm{E} ! x \& \mathrm{CPL} x]$

The relation that obtains between two states of affairs, of which one is more complete than another, Meinong calls "implectation". The less complete state of affairs is said to be implected in the more complete one. For example, the state of affairs intended by the sentence:

$$
\exists x(F x \& G x)
$$

is implected in the state of affairs intended in the sentence: 
which, in turn, is implected in the state of affairs intended in the sentence:

$$
\exists x(F x \& G x \& H x \& P x)
$$

etc. In Meinong's vocabulary (C) is an implectent of $(A)$ and (B), while (B) is an implectent of (A).

The theory of intentionality formulated in Über Möglichkeit und Wahrscheinlichkeitstates, in a nutshell, that what I am really referring to is some complete implectent of a state of affairs that is explicitly specified by my intention. The picture of intentionality becomes complicated in the following way:

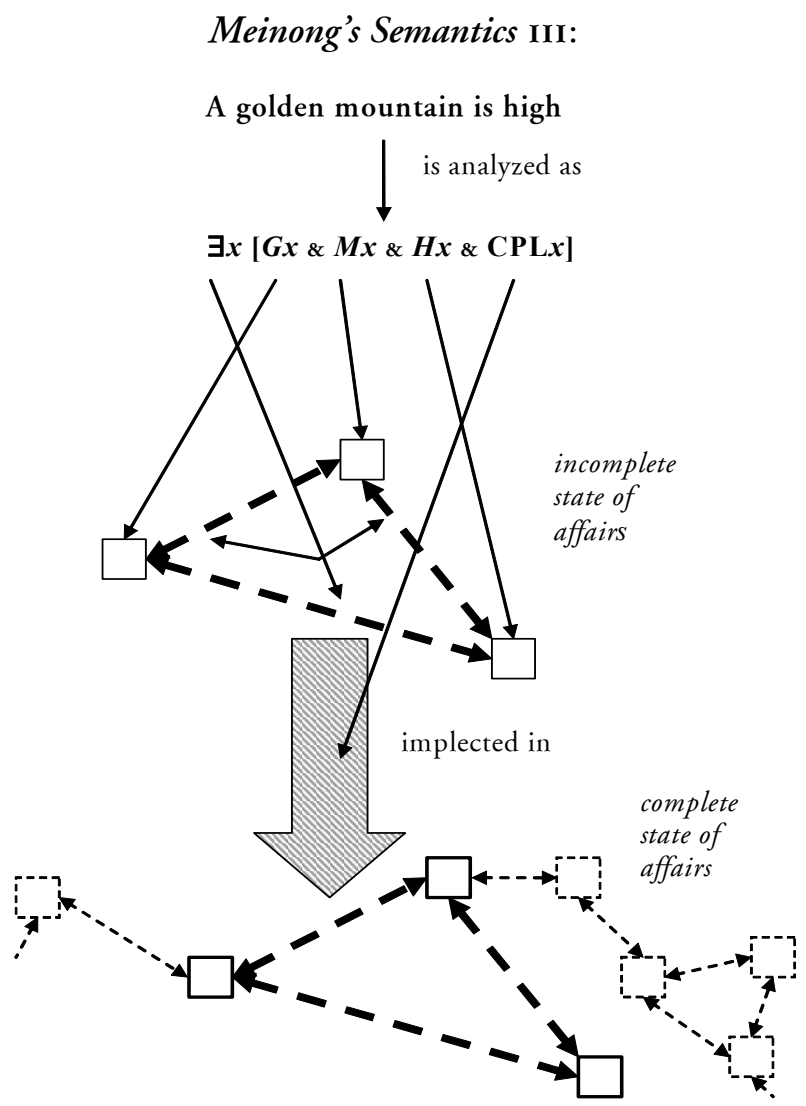


The semantic work of the (implicit) assumption of completeness is to prolong the intention in the realm of complete states of affairs with the help of the relation of implectation.

It's worth pointing out that the later Meinong says that incomplete states of affairs could not obtain at all. Obtaining is the sole privilege of complete ones. This position requires a new definition of truth. According to Meinong's theory of I915, a judgment is true if and only if "its" (incomplete) objective is implected in some obtaining (and a fortiori complete) objective.

\section{WHAT IS A COMPLETE OBJECTIVE?}

But if we ask what must be involved in an objective that deserves to be called "complete", the only possible answer seems to be: everything. Meinong says sometimes that a complete object $x$ is one for which it is specified, with respect to each simple object $y$, whether or not $y$ is connected with $x$. If we restrict the scope of our investigation to the consistent entities, then it seems that a complete objective must be construed as a complete possible world with a definitely specified "place" for each Meinongian simple object. This allows us to reformulate (and simplify) the Meinongian definition of truth: a judgment is true if and only if "its" (incomplete) objective is implected in the actual world.

\section{LEIBNIZIAN DESCRIPTIONS}

Under the assumption of consistency and without restriction to existing objects, we can pick up a unique object only when we specify for each simple object (each property and relation) whether or not it is "connected" with this object. Such a specification amounts to the complete description of a possible world, and so we get the consequence that each object which is specifiable in this way must, in a sense, involve a whole, complete possible world. In this respect it resembles a Leibnizian monad.

If we have a complete description of a world that has a Meinongian form:

$$
\exists x \exists y \exists z \ldots(G x \& M x \& H x \& R x y \& F y \& K y z \& \ldots)
$$

(a cluster of existential quantifiers, followed by an extremely complex formula which specifies for each simple object how it is situated in the 
whole structure of the world), we can say that it specifies each of the objects $x, y, z, \ldots$, completely with respect to the remaining part of the world. Each such object will be, in this sense, like a Leibnizian monad which mirrors the whole world from its perspective.

An important comment is in order here: in the above I have entirely neglected the question of inconsistent objects, which Meinong sometimes seems to discuss. This restriction means that in all the forms that we have investigated so far, there must be an implicit assumption of consistency, which is, of course, the next extra-nuclear property. If we symbolize the consistency predicate as "CON" then the full Meinongian forms will be correspondingly:

\section{Soseinsmeinen: $\exists x[G x \& M x \& H x \& \mathrm{CON} x \& \mathrm{CPL} x]$ \\ Seinsmeinen: $\exists x[G x \& M x \& H x \& \mathrm{CON} x \& \mathrm{E} ! x \& \mathrm{CPL} x]$}

If we accept the intuitively plausible principle that existence implies consistency, then the Seinsmeinen-form could be simplified by the omission of the redundant consistency predicate.

If we were to introduce inconsistent objects, then we would face many further complications. In a para-consistent universe even a complete Leibnizian description will be unable to single out a unique object, for it will always be possible to find an inconsistent object that satisfies this description as well. There are also further difficult problems involved in the idea of inconsistency and/or para-consistency (e.g. the question whether there is only one all-inclusive inconsistent object), which I cannot pursue in this paper. ${ }^{2}$

\section{REFERENCES}

Chrudzimski, Arkadiusz. 200I. "Die Theorie der Intentionalität Meinongs". Dialectica 55: I19-43.

-. 2003. "Quine, Meinong und Aristoteles. Zwei Dimensionen der ontologischen Verpflichtung". Metaphysica 4: 39-68.

- 2005a. "Drei Versionen der Meinongschen Logik". Zeitschrift für Philosophische Forschung 59: 49-70.

- 2005 b. "Abstraktion und Relationen beim jungen Meinong". Meinong Stud-

${ }^{2}$ My work was supported by the Austrian Foundation for the Support of Scientific Research (FWF). 
ies $\mathrm{I}:$ 7-62.

Meinong, Alexius. 1902. Über Annahmen. Leipzig: Johann Ambrosius Barth.

-. 1904. Über Gegenstandstheorie. In Gesamtausgabe. Vol. II: 48I-535.

-. I9Io. Über Annahmen, 2nd edn. In Gesamtausgabe. Vol. IV.

-. I915. Über Möglichkeit und Wahrscheinlichkeit. In Gesamtausgabe. Vol. vi.

-. I969-78. Gesamtausgabe, ed. R. Haller et al. 8 vols. Graz: Akademische Druck- u. Verlagsanstalt.

Russell, Bertrand. 1903. The Principles of Mathematics. With new Introduction: London: Allen and Unwin, 1937.

—. 1905. "On Denoting". Mind n.s. I4: 479-93. Papers 4: 415-27.

—. I9ı. "Some Explanations in Reply to Mr. Bradley". Mind n.s. I9: 373-8.

Papers 6: 354-58. 